\title{
Estructuras de capital político de Diputados Nacionales por la Provincia de Buenos Aires (1999-2015)
}

\author{
Political capital structure of National MPs from Buenos Aires Province (1999-2015) \\ Cintia Rodrigo \\ CONICET/Centro de Estudios Históricos- \\ Universidad Nacional de Mar del Plata, Argentina \\ cintiarodrigo@conicet.gov.ar
}

\section{Resumen:}

El objetivo de este trabajo es describir las estructuras de capital político de los y las Diputadas Nacionales (DN) de la Provincia de Buenos Aires (PBA) del período 1999-2015. Se parte de suponer que estos representantes -los DN- portan una serie de atributos que, combinados, conforman una estructura de capital político que les posibilita ser elegibles y formar parte de uno o más elencos legislativos. A partir de una base de datos inéditos, que contempla el universo de legisladores del período, se construye una tipología emergente que combina un abanico de 8 especies de capital político. Los resultados muestran que les DN llegan a sus cargos con estructuras que combinan centralmente dos y tres especies de capital político, sin que sean relevantes perfiles diferenciales según partidos/alianzas y cohortes. Las trayectorias relevadas muestran que el rasgo distintivo de las estructuras de capital político en la PBA es la militancia partidaria y/o en organizaciones.

Palabras clave: Capital político, Buenos Aires, Diputados Nacionales.

\begin{abstract}
:
This paper aims to describe the political capital structures of National MPs from Buenos Aires Province (1999-2015). This theoretical basis conceives MPs political capital structures as combinations of different political capital species. Structure which make possible them to be elected. This article analyses a non-edited database with autobiographic information about all the MPs for the period. Those data are typified based on 8 attributes. Empiric evidence shows structures mainly based on two or three political capital species. There is no significative difference among parties/coalitions or cohorts. The MPs trajectories shows as a key attribute the activism in parties and other organizations.
\end{abstract}

KEYWORDS: Political capital, Buenos Aires, National mps.

\section{INTRODUCCIÓN}

Este trabajo tiene como objetivo describir las estructuras de capital político de los y las Diputadas Nacionales ${ }^{1}$ (DN) de la Provincia de Buenos Aires (PBA) en el período 1999-2015. El supuesto de partida de este artículo, desde una matriz interaccionista de análisis de las relaciones políticas, es que resulta posible aproximarse a los partidos a través de las características que presenta el personal político que los compone. Evidentemente en la tradición de la ciencia y la sociología políticas existen muchos modos de estudiar a los partidos políticos. Por lo general, describiéndolos como actores colectivos y relegando a segundo plano las interacciones que los constituyen. Este trabajo se afirma, por el contrario, en una perspectiva teórica que concibe a las instituciones como el resultado de relaciones entre actores individuales, relaciones que se sostienen o no cotidianamente (Garfinkel, 2006; Latour, 2008). Es decir, son los actores los que hacen a las instituciones, aunque ellas los excedan. Es una forma poco habitual de concebir este tipo de organizaciones, ya que se apoya en los desarrollos teóricos de una línea reciente de análisis sociológico de las instituciones, 
que las concibe como intrínsecamente amenazadas en su persistencia ante la incertidumbre de los resultados de la interacción que las constituye (Latour, 2013).

En este sentido no sería pertinente, por ejemplo, hablar del accionar de los partidos políticos, ni de las decisiones de los partidos, a menos que sean pensadas como decisiones o acciones de integrantes de esas asociaciones. Vale decir, si los partidos políticos reclutan personal, este reclutamiento sólo es posible que sea realizado prácticamente por actores que forman parte de esos partidos, de modos específicos en cada momento que no pueden ser definidos a priori (Ihl, 2004; Offerlé, 2011b). O, en otra perspectiva, si los partidos dejan de tener impacto en la disputa, o cambian de fisonomía, son sus integrantes quienes realizan esta operación a partir de las estructuras de capital que portan, las cuales hacen posible modificar las relaciones con resultados más o menos inciertos.

Por lo tanto, el modo de ser de los partidos políticos -o su transformación-, el modo de tomar decisiones, de reclutar candidatos, de articular campañas, dependerá en cierta medida de los rasgos de quienes toman esas decisiones, es decir, los integrantes concretos de las estructuras partidarias concretas en cada momento particular. Es el mismo caso el de la definición de las listas de candidatos: si son los líderes partidarios quienes las organizan, ello depende también de qué elementos tienen, qué márgenes de maniobra, qué insumos y qué valoraciones consideran más importantes en función de obtener un triunfo electoral.

En este marco es posible afirmar que los atributos personales y de trayectoria de los representantes de cada partido indican cómo son los partidos políticos en cada momento histórico. Es decir, no se trata de que los partidos elijan algunos candidatos, sino de que un conjunto de actores acuerde presentar a sus exponentes más "elegibles" en cada contienda. Quiénes son y cómo son los individuos es quiénes son y cómo son los partidos políticos, o al menos, sus elencos dirigentes en cada coyuntura (los diputados nacionales en este caso, pero puede pensarse para otras categorías).

Aún si se sostuviera que son los líderes partidarios quienes definen las candidaturas -sin poner en cuestión por ahora la noción de liderazgo y lo que implica-, los representantes de cada partido expresan doblemente de qué están hechos los distintos partidos y cuáles son los mejores elementos con los que cuenta cada uno (o cree mejor). En ese sentido es que se plantea que un análisis descriptivo general permite ver cómo se combinan las variables personales con las organizacionales (Gauja, 2013; Van Haute y Gauja, 2015). Asociar individuos con capitales permite mostrar cómo los partidos cuentan con capitales específicos, que portan sus representantes y que pueden o no transformarse a lo largo del tiempo.

Conociendo si se incorporan nuevos integrantes, si hay permanencia de ciertos individuos, si se dan cambios de partidos/coaliciones, es posible relacionar las transformaciones del escenario político a través de sus elencos generales. El análisis diacrónico de las estructuras de capital político de cada elenco partidario permite responder algunos interrogantes: ¿Son similares o presentan diferencias significativas? ¿Cuáles? ¿Modifican su fisonomía acompasadamente? ¿En distintos ritmos? ¿Los partidos/coaliciones se van haciendo cada vez más heterogéneos en su composición? ¿O son cada vez más homogéneos? ¿En qué difieren o se parecen? ¿Se observa una construcción paulatina de un modo de ser político en clave de profesionalización, que se traduzca en ciertos atributos personales? ¿Cuáles son? La intención general es, desde un enfoque sociológico, caracterizar a los actores políticos para ver cómo construyen un elenco a partir de sus atributos ("un gran elenco" o uno "mediocre" en términos del periodismo de espectáculo es una buena analogía).

En la PBA esto es particularmente importante en relación al peronismo, que es el actor de mayor centralidad en su escenario político desde su surgimiento como partido. El peronismo es central en la PBA pero no presenta un modo estable de organización, por el contrario, modifica la fisonomía de sus estructuras partidarias y coaliciones permanentemente, dando lugar a elencos heterogéneos. Es por ello que realizar una descripción de la fisonomía de sus listas/contingentes legislativos en el período es una de las posibles maneras de asir las transformaciones que experimentó.

La provincia de Buenos Aires es un territorio específico de producción de lo político donde se da una particular imbricación de las instancias nacional y provincial que ha sido descrita como "un empalme puntual 
e irrepetible": nunca los triunfos o derrotas electorales en la provincia son un dato menor para los gobiernos nacionales y, al mismo tiempo, ella sufre un marcado proceso de "nacionalización", un impacto decisivo de la política nacional en su territorio (Ollier, 2010a). En este sentido, el análisis de las características de diputados nacionales puede contribuir a la comprensión del vínculo entre los liderazgos provinciales y nacionales, ya que por la naturaleza del cargo expresan cabalmente dicha imbricación.

Acerca del período seleccionado, vale destacar que en el distrito se inicia con un fenómeno político novedoso. En 1999, cuando se produjo el ascenso de la Alianza a la presidencia de la República, el justicialismo que hegemonizó la Concertación para el Cambio, ganó la gobernación de la provincia de Buenos Aires en virtud de un acuerdo con otras fuerzas, forjado por Eduardo Duhalde. Pese a ser gobernador de la provincia por dos periodos consecutivos (1991-1995; 1995-1999) "el jefe de los barones del conurbano" no pudo impedir que la Alianza se impusiera en las elecciones legislativas. De manera que el control del peronismo sobre el electorado, tanto más cuando el mismo Duhalde, que se presentaba como candidato a presidente, fue derrotado en las elecciones (Ferrari, 2014; Ollier, 2010b).

La posterior debacle de la Alianza y la estrepitosa crisis de 2001 devolvieron centralidad al justicialismo en la vida nacional y provincial, pero también pusieron en evidencia su fragmentación, que a partir de entonces cobró cada vez mayor relevancia en un marco generalizado de desafección política (Novaro, 2006). Las elecciones de 2003 evidenciaron, en la victoria de Néstor Kirchner, el peso del aparato duhaldista. No obstante, desde entonces el partido atraviesa un proceso de fragmentación que se profundiza luego como producto de la disputa Duhalde-Kirchner en 2005 (Ollier, 2010b).

Los comicios de 2007 pusieron en evidencia la personalización de las opciones políticas, dando cuenta de profundas transformaciones en el sistema político provincial. Emergió un escenario con un elevado grado de fragmentación y volatilidad de los apoyos (Rodríguez, 2009). Este escenario se consolidó en las elecciones presidenciales de 2011, en lo que aparece como el momento de afirmación del kirchnerismo como identidad política (Yabkowski, 2012). Como nueva manera de hacer política, el kirchnerismo intentó dar respuesta a las fluctuaciones de un electorado más volátil, con identidades políticas fragmentadas y/o en crisis y con mayor socialización en los mecanismos de la democracia representativa. Sin embargo los años finales de su administración se convirtieron en un período de transición hacia el postkirchnerismo. Las elecciones de 2011 mostraron una serie de realineamientos potenciales de las distintas empresas políticas de filiación peronista. Mostró también la consolidación de alternativas potenciales, en torno al radicalismo y el PRO, que triunfa en 2015 como coalición, terminando así una etapa de control del peronismo de los Ejecutivos nacional y provincial.

En términos globales, las transformaciones operadas en este período se registran tanto en la estructura de los partidos como en su relación con el electorado. Estas modificaciones inciden en el tipo de características y capacidades necesarias para participar exitosamente en el juego político. En tiempos de desafección y de considerable desprestigio de los partidos es preciso no perder de vista que el valor del capital, y la importancia de sus agentes portadores, está profundamente determinado por las propiedades generales de los campos, pero también por sus transformaciones históricas (Joignant, 2012).

En ese marco, el artículo se orienta a conocer las estructuras de capital político de los diputados nacionales por la PBA. Se trata de un grupo de actores relevantes por dos razones. Por una parte, debido a la imbricación entre arenas de distintos niveles de participación que implica su cargo. Por otra, dado su carácter electivo: haber llegado a ocupar esta posición expresa un vínculo bidireccional tanto con las estructuras partidarias que median su postulación como con el electorado que define su elección.

Como ha señalado Joingant (2012), para acceder duraderamente al campo político en alguna de sus arenas (partido, parlamento o congreso, gobierno), ocupando posiciones de dominación en ellas, se requiere estar en posesión de un capital en alguna de sus especies pertinentes en este espacio, así como de una cierta competencia que el primero prefigura. Esta conjunción del capital y de la competencia fue abordada por el 
programa de investigación de Bourdieu, un autor que distinguía entre especies de capital: especies pertinentes de los recursos que son valorados en este espacio en distintos momentos (Bourdieu, 1987; Bourdieu, 2001b).

La unidad de análisis, o, si se quiere, el átomo lógico de la adquisición e inversión del capital, es el actor individual, quien porta un conjunto de atributos altamente variables. En este sentido el capital político puede describirse en términos de estructura (Bourdieu, 1979), noción que remite al peso relativo que tienen las distintas características, relaciones y formas de reconocimiento en el conjunto global de los recursos de los que dispone un individuo o un grupo: un individuo puede ser un profesional destacado fuera del ámbito político (músico, profesor, deportista, actor, médico, etc.), una persona de confianza de un líder (legislador, intendente, gobernador, presidente), un cuadro partidario o sindical (portador, por lo tanto, de un capital político colectivo encarnado en él), y estos atributos constituirán la base para distintos tipos de capital político. Así, el capital político no sólo se inserta en un proceso dinámico de acumulación, sino que tiene distintas variantes: la estructura del capital de un individuo dado implica ciertos atributos incorporados, objetivados e institucionalizados, como así también de relaciones sociales.

El análisis se orienta a conocer qué estructuras de capital político resultan más frecuentes en cada una de las agrupaciones que obtuvieron representación legislativa nacional durante el período. Es decir, a establecer posibles perfiles diferenciales tanto entre partidos como en sucesivas cohortes, teniendo en cuenta también los cambios de partido. Una de las dificultades para retratar al conjunto de los partidos que obtuvieron representación legislativa es la permanente emergencia de nuevos partidos y frentes/coaliciones; por eso, el análisis busca seguir a los individuos, ver su permanencia o no, sus cambios de partidos/coaliciones. Hay actores que hacen existir nuevas coaliciones (o actrices). Mapear a estos actores y las estructuras de capital político que portan es una parte de la cartografía general de los partidos políticos, que requiere ser complementada con otras regiones, pero que puede ayudar a orientarse en la decodificación del paisaje que presenta la política bonaerense.

Algunas de las hipótesis que explora el trabajo son:

1. Las estructuras de capital político presentan complejidades diferenciales según partidos políticos.

2. Una mayor complejidad de la estructura de capital político hace más viable una carrera sostenida, aun cuando se realice uno o más cambios de partido.

Para este trabajo se retoma, modificándola, la propuesta de Joignant. A partir de la literatura científica y estudios empíricos de carreras políticas, que sugieren el predominio de un número limitado de recursos relvantes, el autor identifica nueve especies de capital político: universitario, político militante, político oligárquico, tecnocrático pragmático, tecnocrático político, technopolítico, notoriedad, carisma. Construye así una tipología realista de capitales que "exige ser confirmada o invalidada a partir de investigaciones empíricas" (Joignant, 2012, p. 609).

La reformulación que se realiza aquí retoma cuatro de las especies de capital propuestas, pero modifica las restantes cuatro a partir de un trabajo previo que permitió identificar atributos frecuentes en este tipo de actores en la PBA (Rodrigo, 2018). El resultado es un abanico de dimensiones que, si bien no agotan los atributos pasibles de ser reconvertibles como capital político, reducen considerablemente las combinaciones posibles. Permite observar combinaciones posibles en función de aquellas dimensiones que han sido registradas con mayor frecuencia como relevantes, tanto en la PBA como en otros distritos, países y períodos.

Las cuatro especies de capital son retomadas de la propuesta original por su pertinencia para el caso. En primer lugar, el capital universitario, que consiste en la posesión de un título de grado o posgrado, a partir del cual se acreditan tanto saberes específicos como tránsitos por instituciones que constituyen espacios de socialización política. En segundo lugar, el capital político militante (Matonti y Poupeau, 2004), que implica participación en una estructura partidaria durante periodos prolongados de tiempo, ocupando o no cargos en ella, mediante la cual se acumulan destrezas y redes de relaciones que son recursos potenciales para el 
posterior acceso a un cargo público. En tercer lugar, el capital personal de "notoriedad" y de "popularidad fundado en el hecho de ser conocido y reconocido", que deriva de una reputación derivada de "calificaciones específicas" (Bourdieu, 2001b), que se transforma en una especie política de capital al cabo de un trabajo de reconversión por parte del agente. En cuarto lugar, el capital familiar, que refiere a la existencia de vínculos familiares con actores políticamente activos, de lo que deviene una especie de transferencia no sólo de preferencias políticas, sino también y sobre todo de redes, reputación, clientelas, conexiones con donantes de dinero para eventuales campañas, etc.

Por otra parte, una quinta especie denominada originalmente capital politico oligárquico se traduce para este trabajo como capital politico institucional, ya que para los cargos legislativos puede computarse a partir de la ocupación de cargos públicos previos. Las restantes especies descritas por Joignant no son recuperadas porque no se ajustan al objeto de este trabajo, sino que se orientan a cargos ejecutivos y/o de distintos niveles de gestión. Se trata por una parte del capital tecnocrático que el autor subdivide en tres subespecies: 1- tecnocrático pragmático, 2- tecnocrático político y 3-capital technopolítico o technopol. Por otra, del carisma, capital personal de corte "heroico o profético" descrito tempranamente por Max Weber y que suele asociarse al liderazgo personal. En cambio, se consideran como atributos relevantes para la población analizada otras tres especies de capital: 1- participación sindical, 2- participación en organizaciones sociales y 3 - pertenencia a cohortes que representan un recambio generacional en los elencos legislativos. Se traducen aquí como especies de capital dado que fueron atributos identificados como parte de las trayectorias personales previas a la ocupación del cargo legislativo en la PBA (Rodrigo, 2018).

Cada una de estas ocho especies de capital representa una posible dimensión de la estructura de capital político de cada actor particular, y se la operacionaliza a través de los indicadores que se resumen en el siguiente cuadro:

\begin{tabular}{|l|l|l|l|}
\hline Joignant (2012) & $\begin{array}{l}\text { Dimensiones } \\
\text { PBA[2] }\end{array}$ & Indicadores & Valores \\
\hline Universitario & Universitario & $\begin{array}{l}\text { Carrera } \\
\text { universitaria }\end{array}$ & si/no \\
\hline $\begin{array}{l}\text { Político } \\
\text { militante }\end{array}$ & $\begin{array}{l}\text { Político } \\
\text { militante }\end{array}$ & $\begin{array}{l}\text { Cargos } \\
\text { partidarios } \\
\text { ocupados }\end{array}$ & si/no \\
\hline $\begin{array}{l}\text { Político } \\
\text { oligárquico }\end{array}$ & $\begin{array}{l}\text { Político } \\
\text { institucional }\end{array}$ & $\begin{array}{l}\text { Cargos públicos } \\
\text { ocupados }\end{array}$ & si/no \\
\hline $\begin{array}{l}\text { Tecnocrático } \\
\text { pragmático }\end{array}$ & No & No & - \\
\hline $\begin{array}{l}\text { Tecnocrático } \\
\text { político }\end{array}$ & No & No & - \\
\hline Technopolítica & No & No & - \\
\hline Notoriedad & Notoriedad & Notoriedad & si/no \\
\hline Carisma & No & No & - \\
\hline Familiar & Familiar & $\begin{array}{l}\text { Familiar } \\
\text { políticamente } \\
\text { activo }\end{array}$ & si/no \\
\hline & Asociativo & $\begin{array}{l}\text { Participa en } \\
\text { organizaciones } \\
\text { sociales }\end{array}$ & si/no \\
\hline & $\begin{array}{l}\text { Recambio } \\
\text { generacional }\end{array}$ & Edad de ingreso & $\begin{array}{l}430 \\
\text { menos }\end{array}$ \\
\hline & & si/no \\
\hline
\end{tabular}

Los datos que se presentan en este trabajo son resultado del trabajo sobre una base de datos construida por la autora, procesada mediante SPSS ${ }^{3}$. El análisis retoma estas ocho dimensiones de las trayectorias de los dirigentes (universitaria, militante, política institucional, notoriedad, familia política, sindical, asociativa, 
recambio generacional), que son procesadas considerando los valores que asumen sus respectivos indicadores en cada trayectoria individual. De la combinación de estas 8 dimensiones y sus respectivos indicadores con valores dicotómicos resultan 128 posibles estructuras de capital político. Las categorías de una tipología más acotada que se presentan en el trabajo son resultado del procesamiento, a partir del cual se seleccionaron según su complejidad, los tipos más frecuentes construyendo cuatro tipos: unidimensional, bidimensional, tridimensional y multidimensional. ${ }^{4}$ Para cada una de estas estructuras posibles se identifican, en su interior, los tipos más frecuentes de combinación de especies de capital.

Por otra parte, se construyó una cartografía de elencos partidarios, identificado las estructuras de capital político de sus integrantes, como así también su continuidad o no en el escenario político bonaerense a lo largo del período. Adicionalmente se han identificado las trayectorias de cada actor al interior del elenco legislativo general: su entrada, salida, continuidad, cambio de partido, coalición, cantidad de mandatos sucesivos o discontinuos. De este modo se construyó un mapa de partidos/coaliciones y movimientos de sus integrantes.

\section{Primeros resultados}

En relación con las estructuras de capital político del conjunto de los DN por la PBA del período es posible observar que lo más frecuente es encontrar que los actores presentan principalmente combinaciones de dos o tres especies de capital (sean las que fueren), que dan como resultado una preeminencia de estructuras de tipo tridimensional (38\%) y bidimensional (31\%). El elemento más significativo de esta primera descripción es que las estructuras de mayor complejidad, multidimensionales, no son las que predominan. Es más, en el $22 \%$ que se registra bajo esta categoría se condensan combinaciones de 4, 5, 6 y hasta 8 especies de capital, que evidentemente son minoritarias en la población considerada. Como contracara se observa que en la PBA resulta posible acceder a una banca contando con un único atributo reconvertible en capital político, o especie de capital en términos de este trabajo, al menos para un $9 \%$ de los casos. Estas afirmaciones se basan en los resultados de la indagación realizada. Vale destacar que si se consideraran otros atributos, tales el capital técnico o la confianza personal con un líder, es probable que resultase mayor el porcentaje de estructuras multidimensionales. No obstante, en función de las especies de capital que fueron operacionalizadas en esta primera aproximación, puede trazarse un primer perfil que sirva de insumo para futuros trabajos. 


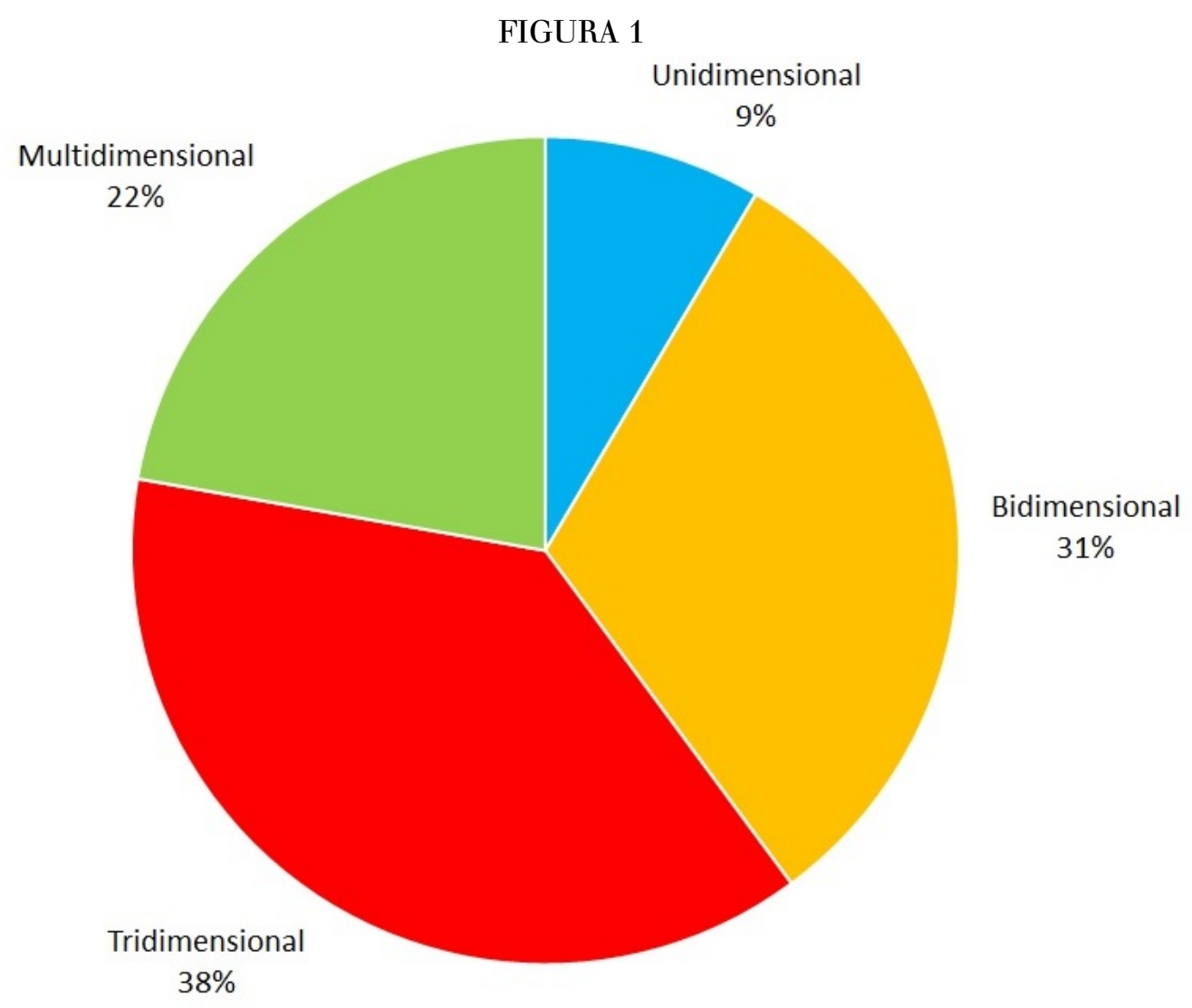

Por otra parte, se puede realizar una lectura en términos de profesionalización, concepto que supone una especialización creciente de quienes forman parte del ámbito político en función del proceso paulatino y sostenido de autonomización que presenta, separando paulatinamente distintos tipos de actores: los profesionales y los profanos (Cfr. Bourdieu, 2001a; Ferrari, 2011; Gaxie, 2004; Offerlé, 2011a). Para este artículo se operacionaliza la profesionalización sincrónicamente, para después realizar una lectura por cohortes de los contingentes en función de los tipos de estructura de capital predominante. En este sentido se mide la profesionalización según el número de especies de capital que porta cada actor particular, siendo más profesionales quienes portan más y menos profesionales quienes portan menos.

Si se parte del supuesto de que la vigencia sostenida de la democracia representativa implica una autonomización paulatina del ámbito político -y por lo tanto una profesionalización de su actividad-, resulta posible inferir que también se construyen paulatinamente estructuras políticas más profesionales y por lo tanto más complejas. En un análisis por cohorte esta hipótesis no se verifica, ya que como puede observarse en la figura 2, la fluctuación en los porcentajes de cada tipo no siguen una tendencia clara a lo largo del período, que culmina con un $28 \%$ de diputados con estructuras de capital político multidimensionales. 
FIGURA 2

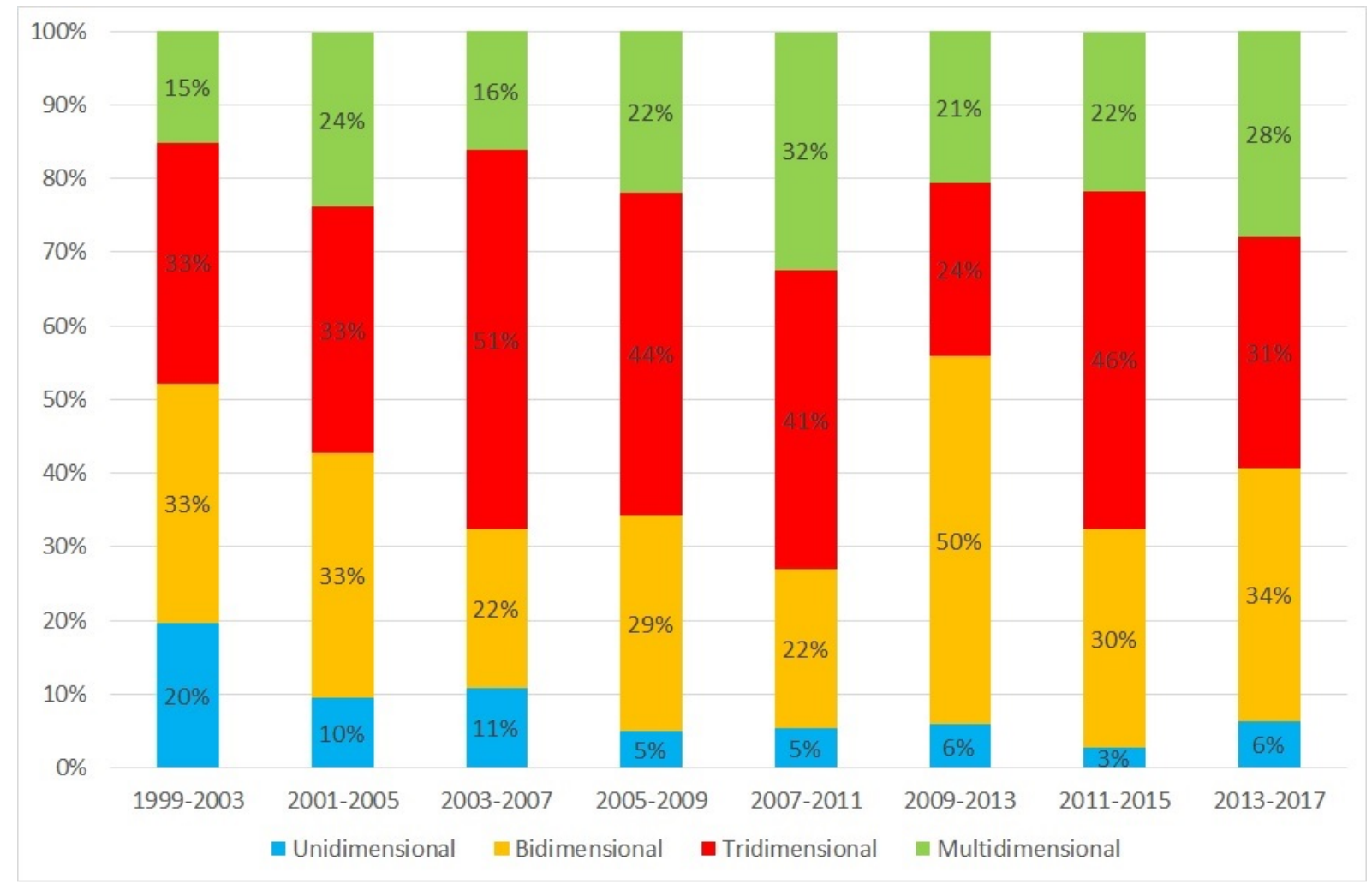

En función del criterio de medición utilizado, es decir, de la cantidad de especies de capital que porta cada actor particular, ${ }^{5}$ la evidencia muestra una preponderancia sostenida -aunque en proporciones variables- de estructuras de tipo bidimensional o tridimensional a lo largo del período, como así también la persistencia de un margen de actores que ingresan a los contingentes legislativos con una estructura de capital político unidimensional (un $8 \%$ en promedio). Es decir, no se verifica la hipótesis de una complejización creciente del acceso al campo para quienes detentan menores niveles de profesionalización al menos para llegar a ocupar el cargo de diputado nacional.

Volviendo a una descripción general del universo es posible identificar al interior de los tipos de estructuras de capital político las combinaciones de especies de capital más frecuentes. ${ }^{6}$ Respecto de las de mayor complejidad -tridimensionales-, se observa que tanto la dimensión de política militante como la universitaria forman parte de casi todas las combinaciones más frecuentes. 


\section{FIGURA 3}

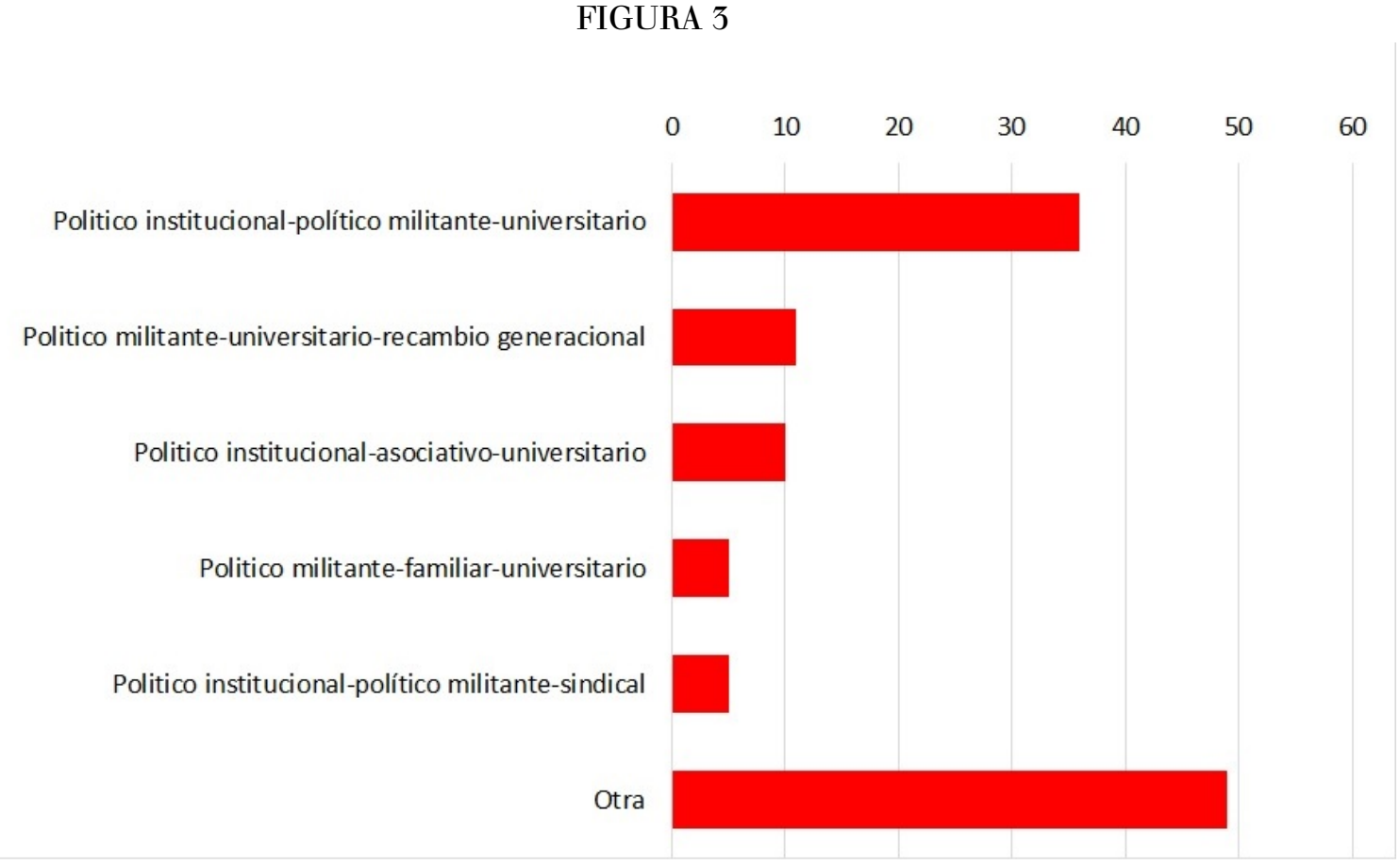

Por otra parte, en cuanto a las estructuras de tipo bidimensional las combinaciones más frecuentes involucran también la dimensión político-militante y el título universitario. Si bien el capital universitario suele formar parte de las especies de capital de las elites (Levita, 2015; Serna, 2005), lo que evidencian estas combinaciones es que para convertirse en $\mathrm{DN}$ tiene mayor peso el tránsito por las estructuras partidarias de manera sostenida, es decir, militante.

\section{FIGURA 4}

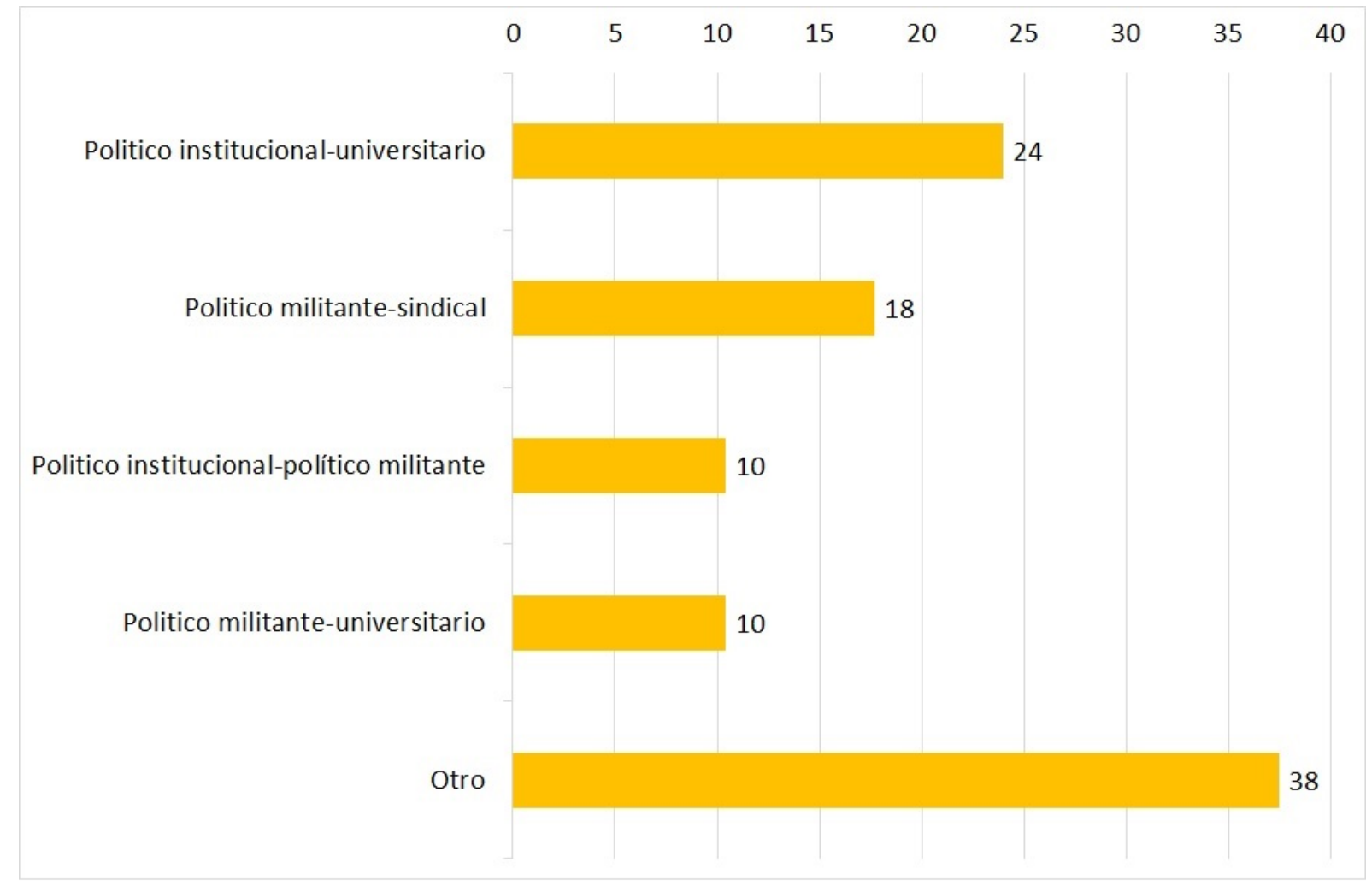


En ambos casos es posible advertir que la pertenencia a una organización es un atributo que está presente en la mayor parte de las combinaciones, pertenencia fundamentalmente a un partido político, pero también otros tipos de afiliación (sindical, asociativa). Aparece entonces el peso de las mediaciones en las carreras políticas, aún en escenarios fluctuantes en términos de partidos/coaliciones.

Como se mencionó anteriormente, retratar al conjunto de los partidos que obtuvieron representación legislativa representa un desafío en la PBA, debido a la permanente emergencia de nuevos partidos y frentes/ coaliciones. A fin de no perder de vista la especificidad de cada elenco se ha optado por mantener las denominaciones registradas por los partidos/coaliciones en la Dirección Nacional Electoral (DNE) para cada una de las cohortes. Para cada elenco partidario se han identificado las estructuras de capital político de sus integrantes, manteniendo la proporción de los elencos al interior de cada cohorte.

FIGURA 5

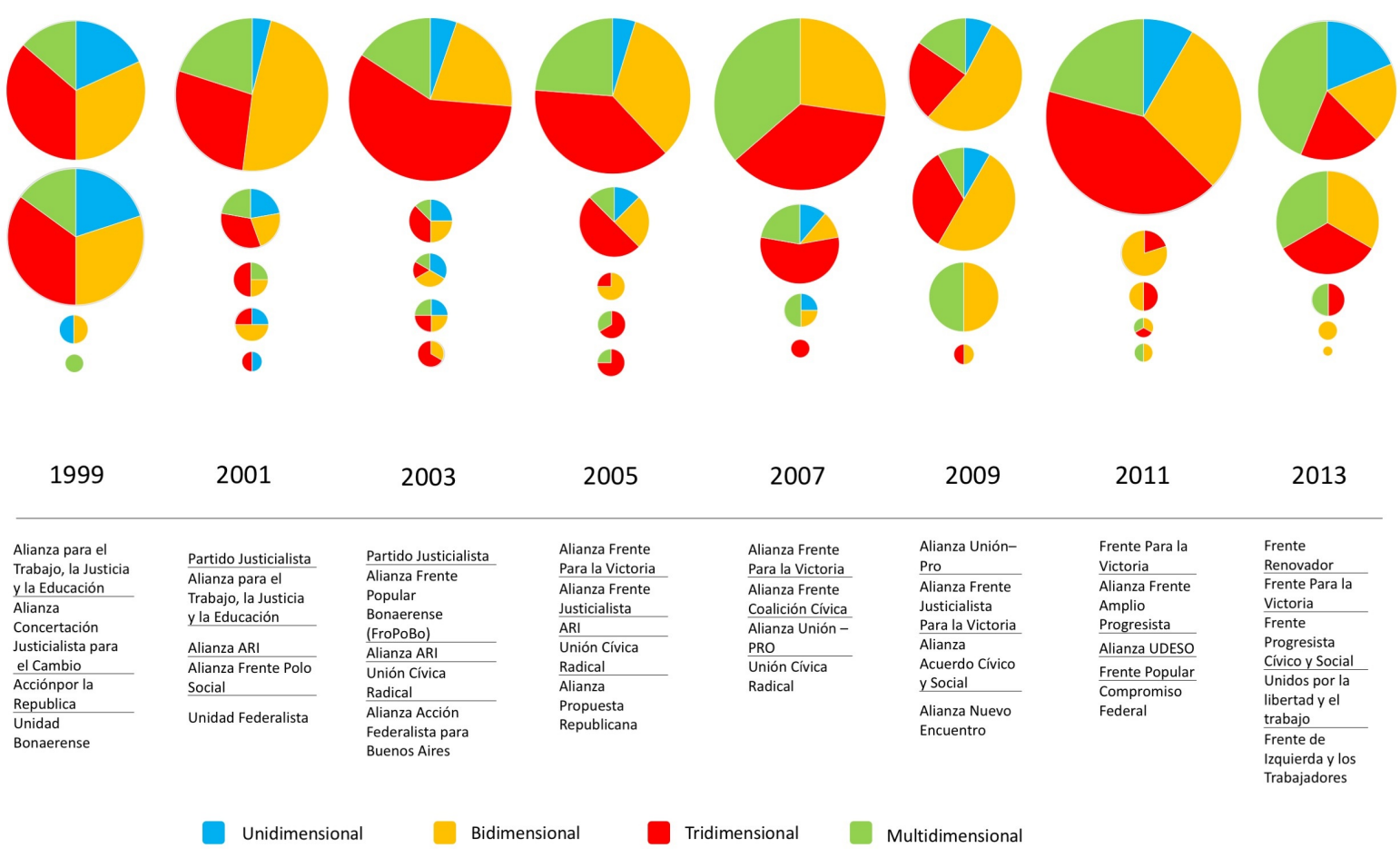

Como se puede observar, los partidos/coaliciones mayoritarias no presentan una lógica uniforme en cuanto a las estructuras de capital político que portan los actores que los integran: si bien parecen predominar estructuras del tipo tridimensional, en la mayor parte del período las fluctuaciones son muy amplias como para expresar una tendencia. En cambio, los partidos minoritarios sí parecen tener una proporción decreciente de actores con estructuras unidimensionales. Esto puede deberse a que iniciarse en la competencia desde una estructura de menor peso en el escenario político implica una apuesta más arriesgada, que sólo cierto tipo de actores estaría dispuesto a realizar: aquellos que tienen mayor cantidad de recursos reconvertibles como capital político en sus trayectorias personales.

Los contingentes representados son muy móviles, es decir que no son los mismos partidos minoritarios los que configuran los elencos en sucesivas cohortes, ni tampoco los mismos partidos/coaliciones mayoritarias. No obstante, los contingentes mayoritarios son en todos los casos de distintos sectores del peronismo (excepto en 1999, que tiene el mismo porcentaje de ingresos a la HCDN que la Alianza). ${ }^{7}$

A partir del seguimiento de las trayectorias individuales es posible observar, además, que los partidos/ coaliciones de la PBA han renovado su personal permanentemente: un total de 231 individuos han ocupado 306 posiciones en el período. La cifra de individuos que tienen un único mandato en el período es de 
176, mientras que sólo 55 renuevan su presencia por dos o más mandatos (23\%). El dato más relevante es que el $75.5 \%$ de los DN registra un paso fugaz por el Congreso. Que un DN no se reelija depende de muchos factores, entre ellos, de que no es un cargo interesante para los políticos argentinos (Burdman, 2010). Respecto de quienes registran más de un mandato, sea por los motivos que fueren, es posible preguntar si existen diferencias en cuanto a la estructura general de capital político. Como se puede observar, entre ellos también predomina el tipo de estructura tridimensional, con mayor incidencia que en el total general. Este subconjunto se compone con las estructuras de mayor complejidad relativa, aunque no exclusivamente.

FIGURA 6

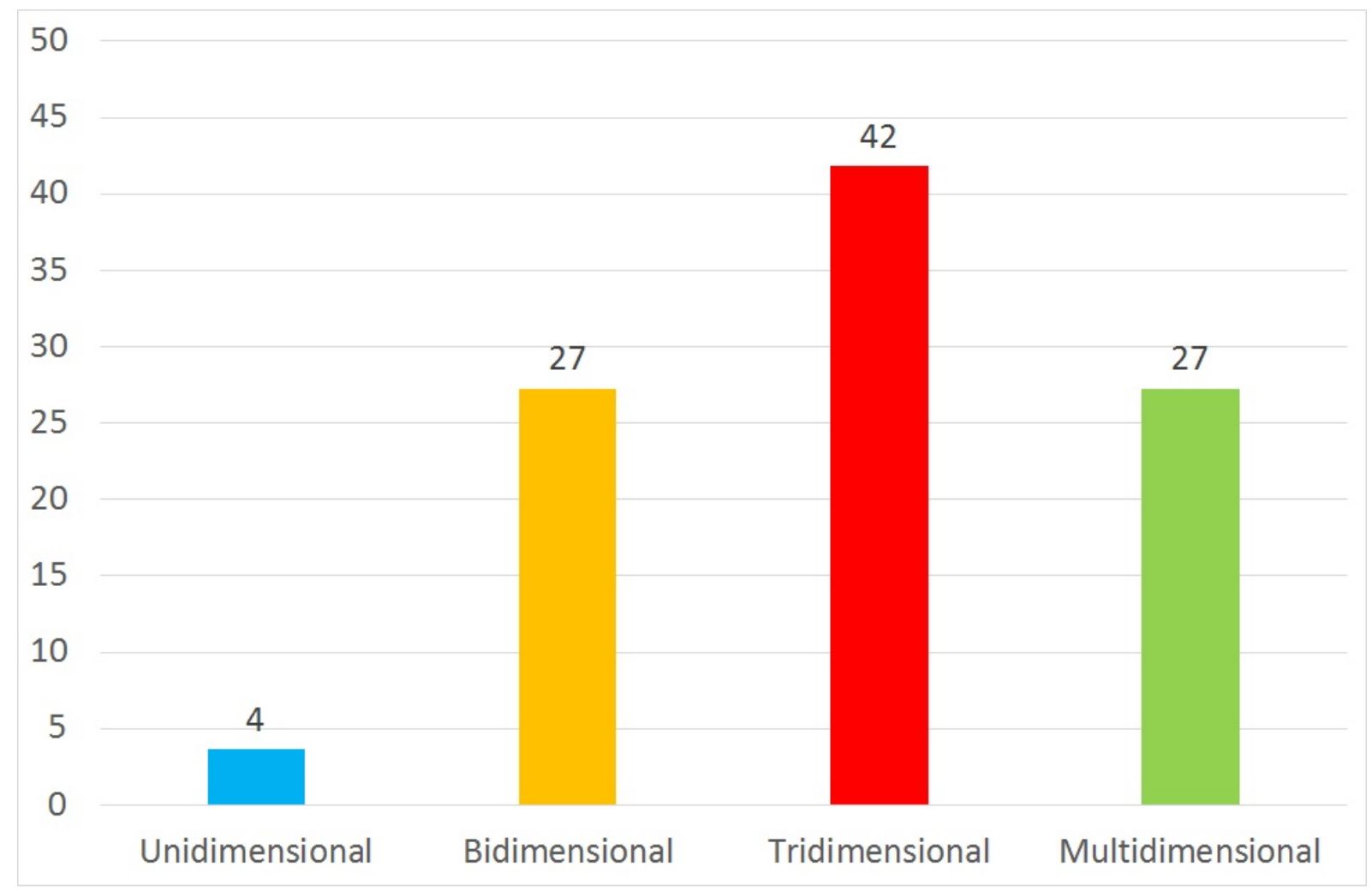

Para complementar la lectura acerca de la importancia de la complejidad de sus estructuras de capital se pueden identificar los recorridos realizados por los DN. De quienes se mantienen por más de un período se ha graficado tanto su pertenencia partidaria de ingreso al cargo como el paso a otro contingente en cohortes sucesivas.

Lo que se puede observar en esta figura es que hay muy pocos casos de DN que se sostienen durante más de dos mandatos y, en los casos en que sucede, no depende de la complejidad de su estructura de capital político. Es decir que el interés por mantenerse como DN y profesionalizarse en la función (y/o los acuerdos realizados al interior de partidos/coaliciones que lo hacen posible para ciertos individuos) es muy minoritario entre los representantes bonaerenses.

Otro elemento que evidencia la figura es que los mayores márgenes de permanencia en el Congreso se dan en los partidos/coaliciones mayoritarios. En particular en la Alianza FPV: 56 \% de quienes ocuparon tres mandatos pertenecen a esta coalición ya sea en el inicio de sus mandatos o siendo incorporados y reelectos. También es posible observar que existe un margen de diputados que sostienen así su permanencia gracias al cambio de partidos/coaliciones. Es el caso de quienes inician sus participaciones como integrantes de la efímera Alianza por el Trabajo la Justicia y la Educación, por el ARI o por la Coalición Cívica. Los cambios en la pertenencia responden a la fluctuación del escenario político durante el período, con coaliciones, partidos y 
alianzas relativamente efímeras. Lo que permite inferir que los cambios de partido y/o coalición no implican discontinuidades en la presencia en el Congreso si no que, por el contrario, la explican en muchos casos.

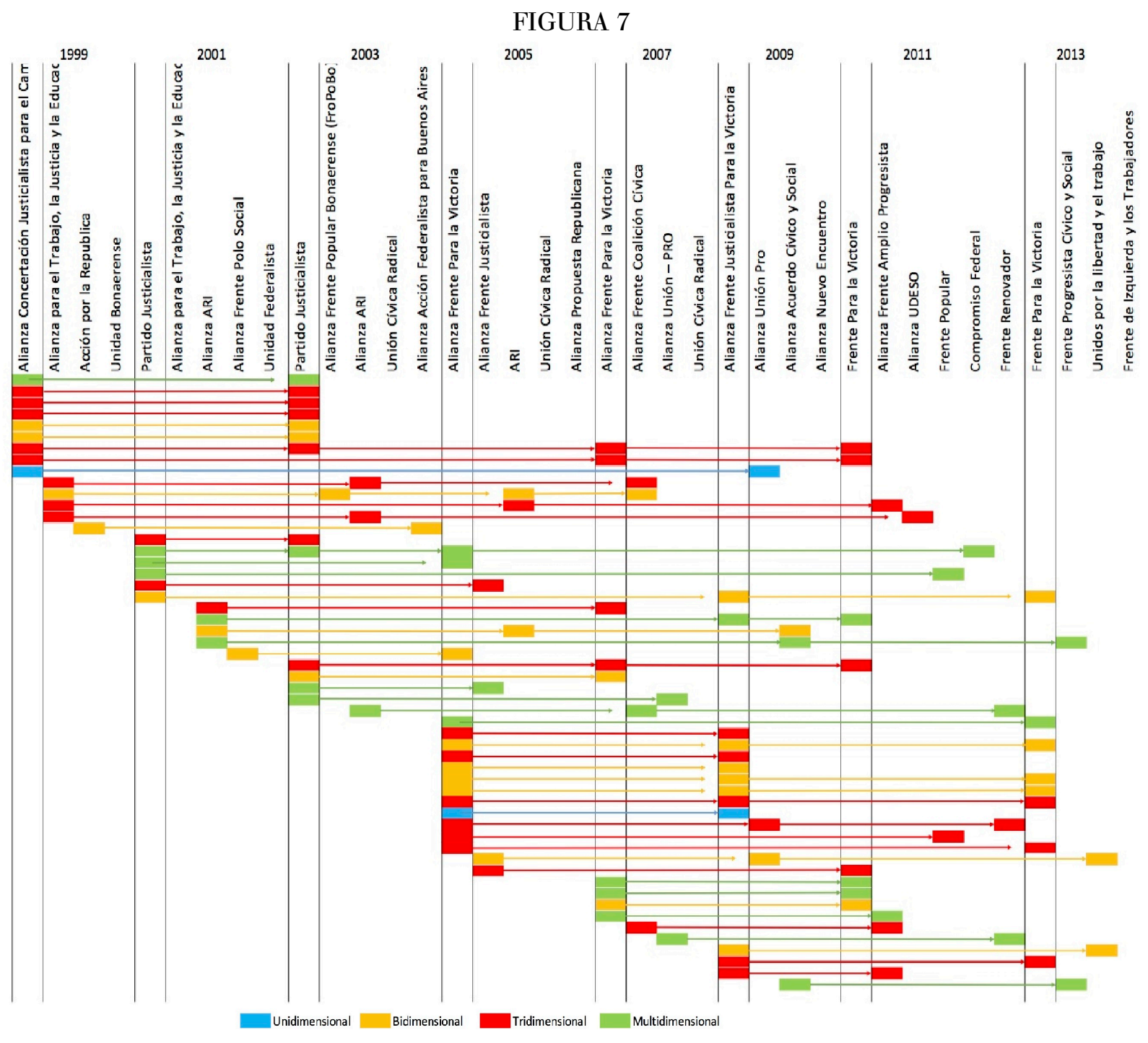

Se puede observar además que existe un "ciclo de continuidad", que puede asociarse con la configuración variable del escenario político. Como se ha señalado previamente, un rasgo central a lo largo del período fue la fragmentación del peronismo, que se hizo evidente a partir de 2003 y se profundizó en 2005 . A ella se sumó el personalismo emergente en 2007 y la consolidación del kirchnerismo como identidad política en 2011.

Estos rasgos parecen haber impactado en las modalidades de organización de los contingentes legislativos del FPV, en el cual se observa un ciclo marcado iniciado en 2005 que se extiende hasta el último recambio completo en 2013. La lectura conjunta del ciclo muestra que el FPV disminuye a partir de 2007 la cantidad de incorporaciones de diputados que reeligen pero, en cambio, se incorporan actores con estructuras de capital multidimensional más que en los restantes períodos. En 2009 disminuye la cantidad de diputados que ingresan y reeligen, pero se consolida una gran parte de las trayectorias iniciadas en 2005. Pero menos de la mitad de estos casos presentan continuidad en el siguiente recambio y se trata de diputados con estructuras bidimensionales mayormente. Esto evidencia que, al menos para el FPV, la continuidad en el cargo no depende de la complejidad de la estructura de capital político que portan los actores. 


\section{A MODO DE CIERRE:}

El recorrido realizado hasta aquí permite sacar algunas conclusiones provisorias. Por una parte, constatar que las estructuras de capital político de los DN de la PBA son altamente heterogéneas y que, si bien se dan algunas regularidades, la dispersión es la norma. Por ello, el modo de organizar la lectura de las estructuras de capital fue a partir de dimensiones - cantidad de dimensiones combinadas en cada actor individual-, ya que entre las biografías consultadas se observa una dispersión en términos de especies de capital que hace difícil, si no inútil, organizar tipologías en función de rasgos específicos.

No obstante, las combinaciones de presentadas - que derivan en grados de complejidad de las estructuraspermiten contar con una imagen global de este tipo de representantes. Ellos son, en general, portadores de dos o tres especies de capital, entre los cuales la militancia partidaria, la experiencia previa en cargos públicos y la posesión de un título universitario aparecen como las más frecuentes y relevantes.

Las combinaciones presentadas emergieron de los datos: sobre las 128 posibles respuestas no se esbozó un recorte a priori, no se presupuso un límite o un piso mínimo de dimensiones a combinar. La consecuencia de esta metodología exploratoria fue la constatación de que estos representantes no son mayoritariamente portadores de estructuras complejas de capital político, aunque tampoco tienen como rasgo común la estructura unidimensional.

Siendo dos o tres sus atributos principales, en su gran mayoría los DN de la PBA son capaces de llegar al Congreso contando con una militancia sostenida en estructuras partidarias. Es necesario decir que estos actores participan en escenarios fluctuantes: no sólo los caudales electorales sino también las propias estructuras que los albergan presentan grandes mutaciones.

El cambio de partidos/coaliciones participantes a lo largo del período puede explicar las trayectorias discontinuas de la mayor parte de los DN; no obstante, las estructuras de capital de los elencos por cohorte y partido/coalición muestran similitudes que permiten advertir como rasgo persistente un bajo nivel de profesionalización entre los representantes bonaerenses.

Los resultados obtenidos en este trabajo exploratorio permiten contar con una imagen más ajustada del universo e indican el camino para la construcción de una muestra en función de las tipologías que permita explorar, ahora, el interés que reviste para los DN de la PBA la actividad política y el modo en que la desarrollan.

\section{ReFERENCIAS}

Bourdieu, P. (1987). Cosas dichas. Barcelona: Gedisa.

Bourdieu, P. (1979). La distinción: criterio y bases sociales del gusto. Madrid: Taurus.

Bourdieu, P. (2001a). El campo político. La Paz: Plural.

Bourdieu, P. (2001b). La representación política. En El campo politico. La Paz: Plural.

Burdman, J. (2010). Alfas, ranas y testimoniales: la cultura política de las elecciones legislativas de medio término en Argentina. POSTdata 15(1), 33-74.

Ferrari, M. (2011). Acerca de los políticos y la profesionalización de la política. PolHis 4(7), 79-164.

Ferrari, M. (2014). Entre historia y memoria: la política bonaerense desde la reconstrucción democrática, 1983-2001. En G. de Amézola (Ed.), Historia de la provincia de Buenos Aires [Tomo 5] (pp. 237-278). Buenos Aires: UNIPE.

Garfinkel, H. (2006). Estudios en etnometodología. Barcelona: Antrophos.

Gauja, A. (2013). The Politics of Party Policy From Members to Legislators. Hampshire: Palgrave Macmillan UK.

Gaxie, D. (2004). La democracia representativa. Santiago: LOM Ediciones.

Van Haute, E., y Gauja, A. (2015). Party members and activist. New York: Routledge.

Ihl, O. (2004). El voto. Santiago: LOM Ediciones. 
Joignant, A. (2012). Habitus, campo y capital. Elementos para una teoría general del capital político. Revista Mexicana de Sociología 74(4), 587-618.

Latour, B. (2008). Reensamblar lo social: una introducción a la teoria del actor-red. Buenos Aires: Manantial.

Latour, B. (2013). Investigación sobre los modos de existencia: Una antropologia de los modernos. Buenos Aires: Paidós.

Levita, G. (2015). La política como profesión: perfiles y tipos de trayectorias de los senadores argentinos. TELOS. Revista de Estudios Interdisciplinarios en Ciencias Sociales, 17, 38-57.

Matonti F. y Poupeau F. (2004). Le capital militant. Essai de definition. Actes de la recherche en sciences sociales, 155, 4-11.

Novaro, M. (2006). Historia de la Argentina Contemporánea. De Perón a Kirchner. Buenos Aires: Edhasa.

Offerlé, M. (2011a). Los oficios, la profesión y la vocación de la política. PolHis, 7, 84-99.

Offerlé, M. (2011b). Perimetros de lo politico. Contribuciones a una socio-historia de lo político. Buenos Aires: Antropofagia.

Ollier, M. M. (2010a). Atrapada sin salida. Buenos Aires en la politica nacional. 1916-2007. San Martin: UNSAM Edita.

Ollier, M. M. (2010b). Kirchner al poder institucional e informal (2003-2010). Temas y Debates, 20, 39-58.

Rodrigo, C. (2018). Convertirse en representante: trayectorias y carreras políticas de diputados nacionales bonaerenses. Sociología epolitica, 26(67), 91-105.

Rodríguez, D. (2009). Un nuevo capítulo de la crisis de los partidos bonaerenses: acción del liderazgo presidencial y fragmentación política en el proceso electoral 2007. En I. Cheresky (Ed.), Las urnas y la desconfianza ciudadana. Rosario: Homo Sapiens.

Serna, M. (2005). Las vías hacia el poder político. Bases sociales y carreras parlamentarias. En E. Mazzei (Ed.), El Uruguay desde la Sociología IV. Montevideo: UDELAR.

Yabkowski, N. (2012). El kirchnerismo como temporalidad inesperada. En M. Barros, A. Daín y M. Morales (Eds.), Escritos $K$. Villa María: Eduvim. 


\section{Anexo}

TABLA 1

Partidos y Alianzas que obtuvieron bancas en el Congreso, PBA, 1999-2015

\begin{tabular}{|c|c|c|}
\hline Año & Partido o Alianza & Bancas \\
\hline \multirow[t]{4}{*}{1999} & $\begin{array}{l}\text { Alianza para el Trabajo, la Justicia y la } \\
\text { Educación }\end{array}$ & 16 \\
\hline & $\begin{array}{l}\text { Alianza Concertación Justicialista para } \\
\text { el Cambio }\end{array}$ & 16 \\
\hline & Acción por la Republica & 2 \\
\hline & Unidad Bonaerense & 1 \\
\hline \multirow[t]{5}{*}{2001} & Partido Justicialista & 18 \\
\hline & Alianza Frente Polo Social & 4 \\
\hline & Alianza ARI & 4 \\
\hline & $\begin{array}{l}\text { Alianza para el Trabajo, la Justicia y la } \\
\text { Educación }\end{array}$ & 7 \\
\hline & Unidad Federalista & 2 \\
\hline \multirow{5}{*}{2003} & Partido Justicialista & 19 \\
\hline & $\begin{array}{l}\text { Alianza Frente Popular Bonaerense } \\
\text { (FroPoBo) }\end{array}$ & 5 \\
\hline & Alianza ARI & 4 \\
\hline & Unión Civica Radical & 4 \\
\hline & $\begin{array}{l}\text { Alianza Acción Federalista para Buenos } \\
\text { Aires }\end{array}$ & 3 \\
\hline \multirow[t]{5}{*}{2005} & Alianza Frente Justicialista & 8 \\
\hline & ARI & 3 \\
\hline & Unión Civica Radical & 3 \\
\hline & Alianza Propuesta Republicana & 3 \\
\hline & Alianza Frente Para la Victoria & 18 \\
\hline \multirow[t]{4}{*}{2007} & Alianza Frente Para la Victoria & 20 \\
\hline & Alianza Frente Coalición Civica & 9 \\
\hline & Alianza Unión - PRO & 4 \\
\hline & Unión Civica Radical & 2 \\
\hline \multirow[t]{4}{*}{2009} & Alianza Nuevo Encuentro & 2 \\
\hline & Alianza Unión Pro & 13 \\
\hline & Alianza Acuerdo Civico y Social & 8 \\
\hline & $\begin{array}{l}\text { Alianza Frente Justicialista Para la } \\
\text { Victoria }\end{array}$ & 12 \\
\hline \multirow[t]{5}{*}{2011} & Alianza UDESO & 3 \\
\hline & Frente Popular & 2 \\
\hline & Compromiso Federal & 2 \\
\hline & Alianza Frente Amplio Progresista & 5 \\
\hline & Frente Para la Victoria & 22 \\
\hline \multirow[t]{5}{*}{2013} & Frente Progresista Cívico y Social & 4 \\
\hline & Frente Para la Victoria & 12 \\
\hline & Frente Renovador & 16 \\
\hline & Frente de Izquierda y los Trabajadores & 1 \\
\hline & Unidos por la libertad y el trabajo & 2 \\
\hline
\end{tabular}

Fuente: elaboración propia en base a datos de la Dirección Nacional Electoral

\section{Notas}

1 Este artículo refiere a diputadas y diputados, no obstante, se les referirá de aquí en más usando el masculino como expresión general, debido a su carácter hegemónico en un lenguaje profundamente androcéntrico como el español. Es de esperar que en futuros trabajos sea la norma el uso de fórmulas neutras, en aras de una mayor equidad y de la nominación no binaria de los géneros. 
2 Dimensiones que permitirán construir una estructura de capital político, pensándolo como una combinación de atributos mensurables, seleccionados a partir de las características generales que han sido descritos para la población de los DN de la PBA en trabajos anteriores (Ver Rodrigo 2018).

3 Base de datos elaborada por la autora, que reúne información del universo de 231 diputados nacionales de la PBA del periodo 1999-2015, distribuidos en 8 cohortes sucesivas.

4 Tipología emergente a partir de los datos que contempla estructuras de complejidad creciente, desde un mínimo por poseer un único atributo reconvertible en capital político hasta un máximo que combina cuatro o más especies de capital.

5 Para realizar un análisis en clave de profesionalización podrían considerarse otras variables, tales como la cantidad de años en política o determinada cantidad de cargos electivos y no electivos. No obstante, en este trabajo se ha optado por sostener una medición dicotómica de ocupación de cargos políticos y partidarios (si/no) en aras de sostener la comparabilidad de trayectorias al momento de ingresar al cargo. Otra decisión metodológica implicaría complejizar la lectura diacrónica considerando, por ejemplo, la ocupación sucesiva de cargos a lo largo del período analizado, tarea que excede las posibilidades de ser realizada en esta primera indagación.

6 En este caso se ha optado por mantener los nombres de las dimensiones, a fin de evitar la confusión con sucesivas taxonomías, agrupando en la categoría otra las demás combinaciones posibles que registran 4 casos o menos, resultando poco significativas estadísticamente.

7 Una lista completa de partidos/coaliciones y escaños obtenidos en cada cohorte se presenta en el anexo. 